\title{
Student Team Achievement Division dan Group Investigation sebagai Teknik Pembelajaran untuk Meningkatkan Kemampuan Mahasiswa dalam Menganalisis Teks Pada Proses Penerjemahan
}

\author{
Yuli Kuswardani \\ Universitas PGRI Madiun, Jl. Setiabudi No. 85 Kota Madiun, Indonesia \\ e-mail: ikuswardaniae@gmail.com
}

\begin{abstract}
Abstrak
Artikel ini mendeskripsikan penerapan teknik pembelajaran Student Team Achievement Division (STAD) dan Group Investigation (GI) dalam tahap analisis pada praktik menerjemahkan pada mata kuliah Translation 2 prodi Pendidikan Bahasa Inggris Universitas PGRI Madiun. Untuk menerjemahkan teks mahasiswa harus mampu menganalisis teks bahasa sumber (Tsu) dengan baik. Sebagian besar mahasiswa mengalami kesulitan dalam menganalisis Tsu dengan benar. Untuk mengatasi masalah tersebut STAD dan GI diterapkan dalam praktik penerjemahan. Sampel penelitian adalah mahasiswa semester 7. Data diperoleh melalui observasi, dokumentasi, dan wawancara. Analisis data menggunakan model interaktif. Analisis Tsu dilakukan melalui sesi penyajian - tanya jawab - perbaikan - penyajian hasil revisi analisis Tsu - penentuan hasil analisis. Hasil analisis Tsu mahasiswa menunjukkan peningkatan meskipun belum sangat baik. Mahasiswa lebih antusias dalam menerjemahkan karena mahasiswa bisa menganalisis Tsu dengan berdiskusi dalam kelompok belajar dan diskusi kelas.
\end{abstract}

Kata kunci: STAD; Gl; analisis teks; kemampuan mahasiswa; proses penerjemah

\section{The Application of Student Team Achievement Division (STAD) and Group Investigation (GI) to Improve Students' Ability in Analyzing Texts as Process of Translation}

\begin{abstract}
This study aims at describing the application of Student Team Achievement Division and Group Investigation teaching approaches in analyzing texts on translating practices in translation 2 at Department of English Teaching Universitas PGRI Madiun. To translate source language text students should be able to analyze it. Most students get problems to analyze texts. To overcome problems suitable teaching, approaches are needed. Those two teaching approaches were applied to solve problems existing in teaching and learning process of Translation 2. The subject of the study was the seventh semester students. Data sources were gained from observation, documentation, and interview. Data analysis was done by using the interactive models. The analysis of SLT (Source Language Text) was through doing presentation discussion - revision - presentation of SLT analysis revision result - final result sections. Students' analysis result shows the improvement of students' ability in analyzing SLT. Students are also more enthusiastic in translating SLT since they can analyze SLT in group and through conducting class discussion.
\end{abstract}

Keywords: STAD; Gl; Text analysis; Students' ability; Process of Translation 


\section{Pendahuluan}

Proses penerjemahan secara garis besar meliputi analisis (analyzing), pengalihan (transferring), dan penyusunan kembali (restructuring). Semua tahap dalam satu siklus penerjemahan merupakan satu kesatuan yang utuh dan saling mempengaruhi. Jika seorang penerjemah melakukan kesalahan dalam salah satu tahap maka hal itu akan menimbulkan kesalahan pada tahap berikutnya sehingga kualitas hasil terjemahannya menjadi tidak baik.

Analisis teks sumber (Tsu) merupakan tahap pertama dalam proses penerjemahan yang sangat menentukan kualitas hasil terjemahan. Analisis Tsu wajib dilakukan karena penerjemah harus memahami Tsu secara komprehensif dan lengkap (Nord, 1991: 1-2). Lebih lanjut, Tsu harus dipahami secara menyeluruh dan diinterpretasikan dengan benar. Karnedi (2014: 1.1) menjelaskan bahwa analisis Tsu bertujuan untuk menjelaskan atau mengantisipasi ciri-ciri linguistis dan struktur Tsu dalam kaitannya dengan sistem dan norma atau kaidah yang berlaku dalam bahasa sumber (Bsu). Selanjutnya, penerjemah berdasarkan pada hasil analisis akan dapat menentukan keputusan atau pilihan yang harus diambil pada proses penerjemahan.

Agar bisa dihasilkan analisis Tsu yang tepat seperti tersebut di atas bukanlah hal yang mudah. Samuelsson-Brown (dalam Sujono 2014: 1) menyatakan bahwa seorang penerjemah harus memiliki pemahaman yang baik terhadap teks yang dia terjemahkan. Makna suatu kalimat tidak dihasilkan dari akumulasi makna kata-kata yang menyusun kalimat itu, yang dikenal sebagai semantik komposisional, maka penerjemah harus benar-benar memahami makna dari rangkaian kata-kata dalam kalimat itu (Samiati, 2012: 71). Jadi agar mampu memahami kalimat yang diterjemahkan penerjemah harus memahami kaidah yang berlaku dalam Bsu.

Kemampuan mahasiswa prodi Pendidikan Bahasa Inggris dalam menganalisis Tsu masih kurang baik. Pada umumnya kemampuan mahasiswa baru meliputi analisis kalimat dengan hanya mengenal subyek dan predikat. Pengertian fungsi kata dan unsur kalimat yang ada dalam suatu kalimat yang kompleks belum bisa dipahami dengan benar. Menurut pengalaman peneliti, bila mahasiswa diberikan teks yang didalamnya terdiri dari banyak kalimat yang mempunyai struktur yang kompleks maka mahasiswa hanya akan menganalisis teks itu sekilas saja sedangkan analisis Tsu dalam proses penerjemahan mengharuskan mahasiswa untuk mengenal pola kalimat dengan variasinya. Tentu saja analisis kalimat yang hanya sekilas saja tidak bisa dijadikan dasar bagi mahasiswa untuk melanjutkan proses penerjemahan pada tahap kedua dan ketiga, yaitu transferring dan restructuring. Dengan demikian hasil terjemahan tidak akan bisa memenuhi kriteria kualitas terjemahan yang bagus, yang memenuhi unsur-unsur akurasi, kealamiahan, dan keterbacaan.

Pengetahuan mahasiswa tersebut belum memadai untuk digunakan sebagai dasar dalam menerjemahkan teks. Untuk meningkatkan kemampuan mahasiswa dalam menganalisis Tsu dalam praktik menerjemahkan, maka diperlukan teknik pembelajaran yang sesuai dengan kondisi mahasiswa dan diharapkan dapat menjadi solusi untuk mengatasi masalah yang ada. Dalam proses belajar mengajar diperlukan teknik pembelajaran yang dapat memberikan kesempatan bagi mahasiswa untuk secara aktif membangun pengetahuan sendiri melalui proses berpikir sendiri dengan menekankan pentingnya belajar bersama-sama dengan saling membantu satu sama lainnya sebagai satu tim.

Teknik pembelajaran Student Team Achievement Division (STAD) dan Group Investigation (GI) merupakan teknik pembelajaran dalam cooperative learning (pembelajaran kooperatif) yang dapat diterapkan dalam mata kuliah translation 2 agar menjadi solusi permasalahan yang selama ini dihadapi mahasiswa. Teknik pembelajaran STAD menekankan pada aktivitas dan interaksi diantara mahasiswa untuk saling memotivasi dan membantu dalam menguasai materi untuk meraih hasil yang maksimal. STAD dapat diterapkan dengan membentuk kelompok-kelompok belajar yang terdiri dari 4-5 orang mahasiswa secara heterogen (Isjoni, 2007: 51).

Upaya untuk mencapai tujuan yang ditetapkan dari proses belajar mengajar dalam mata kuliah translation 2 juga perlu diimbangi dengan implementasi teknik pembelajaran yang lain yang dapat dikombinasikan untuk diterapkan bersama-sama dalam kelas. Group Investigation (GI) adalah teknik pembelajaran yang juga diterapkan dalam proses belajar mengajar dalam mata kuliah translation 2. Implementasi STAD dan GI diperlukan dalam kelas translation 2 karena kedua teknik pembelajaran ini sesuai dengan kondisi kelas, tingkat kemampuan mahasiswa, dan latar belakang mahasiswa. STAD dan GI diharapkan bisa mengubah sifat pembelajaran dalam kelas dari teacher-centered menjadi student-centered agar tercipta situasi belajar yang dapat mengkondisikan mahasiswa untuk berkomunikasi dan berinteraksi sosial dengan mahasiswa yang lain untuk mencapai tujuan pembelajaran. Teknik pembelajaran tersebut melatih mahasiswa tentang ketrampilan komunikasi dan bekerja dalam suatu kelompok.

Linguista Vol. 2, No. 2, Desember 2018: $106-112$ 


\section{Metode Penelitian}

Penelitian ini adalah penelitian deskriptif kualitatif yang mendeskripsikan implementasi teknik pembelajaran STAD dan GI dalam menganalisis Tsu pada praktik menerjemahkan. Sumber data penelitian ini yaitu mahasiswa semester $7 \mathrm{~A}$, hasil observasi dan hasil wawancara tentang implementasi teknik pembelajaran STAD dan GI dalam menganalisis Tsu, dan dokumen yang terdiri dari hasil analisis Tsu mahasiswa. Teknik yang digunakan untuk menentukan sampel adalah purposive sampling. Sample penelitian ini adalah mahasiswa dan hasil terjemahan mahasiswa. Data dalam penelitian ini digali dengan teknik pengumpulan data observasi, wawancara, dan dokumentasi. Peneliti menerapkan triangulasi sumber, rnetode, dan penyidik untuk peningkatan validitas. Penelitian ini menerapkan analisis model interaktif yang dikemukakan oleh Miles dan Huberman (1994: 20) yang meliputi reduksi data, sajian data dan penarikan simpulan.

\section{Hasil dan Pembahasan}

Penerapan STAD dan GI dalam menganalisis Tsu pada praktik menerjemahkan dapat dirangkum dan disajikan dalam tabel berikut ini:

Tabel 1. Analisis Tsu 1: The Mask Maker

\begin{tabular}{lllll}
\hline & $\begin{array}{l}\text { Identifikasi ciri- } \\
\text { ciri Tsu }\end{array}$ & Struktur Tsu & $\begin{array}{l}\text { Faktor } \\
\text { referensial }\end{array}$ & $\begin{array}{l}\text { Penanda } \\
\text { kohesi }\end{array}$ \\
\hline Kelompok 1 & Baik & Kurang Baik & Baik & Kurang Baik \\
\hline Kelompok 2 & Kurang Baik & Baik & Baik & Baik \\
\hline Kelompok 3 & Baik & Baik & Baik & Kurang Baik \\
\hline Kelompok 4 & Baik & Kurang Baik & Baik & Kurang Baik \\
\hline Kelompok 5 & Baik & Baik & Baik & Baik \\
\hline
\end{tabular}

Tabel 2. Analisis Tsu 2: Genetic Diversity

\begin{tabular}{|c|c|c|c|c|}
\hline & $\begin{array}{l}\text { Identifikasi ciri- } \\
\text { ciri Tsu }\end{array}$ & Struktur Tsu & $\begin{array}{l}\text { Faktor } \\
\text { referensial }\end{array}$ & $\begin{array}{l}\text { Penanda } \\
\text { kohesi }\end{array}$ \\
\hline Kelompok 1 & Baik & Baik & Baik & Baik \\
\hline Kelompok 2 & Baik & Baik & Baik & Baik \\
\hline Kelompok 3 & Baik & Baik & Sangat baik & Baik \\
\hline Kelompok 4 & Baik & Kurang Baik & Baik & Kurang Baik \\
\hline Kelompok 5 & Baik & Baik & Sangat baik & Baik \\
\hline \multicolumn{5}{|c|}{ Tabel 3. Analisis Tsu 3: In Praise of Education } \\
\hline & $\begin{array}{l}\text { Identifikasi ciri- } \\
\text { ciri Tsu }\end{array}$ & Struktur Tsu & $\begin{array}{l}\text { Faktor } \\
\text { referensial }\end{array}$ & $\begin{array}{l}\text { Penanda } \\
\text { kohesi }\end{array}$ \\
\hline Kelompok 1 & Baik & Baik & Baik & Baik \\
\hline Kelompok 2 & Baik & Baik & Baik & Baik \\
\hline Kelompok 3 & Sangat baik & Baik & Sangat baik & Baik \\
\hline Kelompok 4 & Baik & Baik & Baik & Baik \\
\hline Kelompok 5 & Sangat baik & Baik & Sangat baik & Baik \\
\hline \multicolumn{5}{|c|}{ Analisis Tsu 4: Silas Marner } \\
\hline & $\begin{array}{l}\text { Identifikasi ciri- } \\
\text { ciri Tsu }\end{array}$ & Struktur Tsu & $\begin{array}{l}\text { Faktor } \\
\text { referensial }\end{array}$ & $\begin{array}{l}\text { Penanda } \\
\text { kohesi }\end{array}$ \\
\hline Kelompok 1 & Sangat baik & Baik & Baik & Baik \\
\hline Kelompok 2 & Baik & Baik & Baik & Baik \\
\hline Kelompok 3 & Baik & Baik & Baik & Baik \\
\hline Kelompok 4 & Baik & Baik & Baik & Baik \\
\hline Kelompok 5 & Sangat baik & Baik & Sangat baik & Baik \\
\hline
\end{tabular}


Analisis Tsu 5: The Question of Translation and Translation Studies

\begin{tabular}{lllll}
\hline & $\begin{array}{l}\text { Identifikasi ciri- } \\
\text { ciri Tsu }\end{array}$ & Struktur Tsu & $\begin{array}{l}\text { Faktor } \\
\text { referensial }\end{array}$ & $\begin{array}{l}\text { Penanda } \\
\text { kohesi }\end{array}$ \\
\hline Kelompok 1 & Baik & Baik & Baik & Baik \\
\hline Kelompok 2 & Baik & Baik & Baik & Baik \\
\hline Kelompok 3 & Sangat baik & Baik & Sangat baik & Baik \\
\hline Kelompok 4 & Baik & Baik & Baik & Baik \\
\hline Kelompok 5 & Sangat baik & Baik & Sangat baik & Baik \\
\hline
\end{tabular}

Teknik pembelajaran STAD dan GI diterapkan dalam salah satu tahap dalam proses penerjemahan yaitu analysis. STAD dan GI diterapkan untuk menganalisis Tsu pada saat menerjemahkan teks dalam mata kuliah translation 2. Tugas mahasiswa yaitu: (1) menganalisis Tsu dengan cara berdiskusi dengan kelompok belajarnya masingmasing dan melaporkan hasil analisisnya secara individual dalam lembar kerjanya masing-masing pada dosen, (2) mempresentasikan hasil analisis bersama-sama dengan anggota kelompoknya untuk satu teks yang berbeda antarkelompok.

Tsu yang diberikan dosen untuk dianalisis yaitu The Mask Maker, Genetic Diversity, In Praise of Education, Silas Marner, dan The Question of Translation and Translation Studies. Teks tersebut merupakan teks dengan jenis yang berbeda. Pemilihan jenis teks yang berbeda didasarkan pada pertimbangan tertentu, yaitu agar mahasiswa memahami perbedaan teknik analisis untuk jenis teks yang berbeda. Jenis teks yang berbeda akan membutuhkan teknik analisis yang berbeda pula.

Analisis Tsu yang dilakukan mahasiswa meliputi beberapa aspek yaitu identifikasi ciri-ciri Tsu, struktur Tsu, faktor referensial, dan penanda kohesi. Analisis Tsu tersebut bila dijabarkan lebih lanjut mencakup pola kalimat, stuktur bahasa, kolokasi, idiom, gaya bahasa, konteks dan sebagainya. Selain itu beberapa aspek lain yang juga merupakan aspek yang dianalisis yaitu tujuan penulisan teks oleh penulis teks dan khalayak pembaca yang akan membaca teks hasil terjemahan itu.

Hasil analisis Tsu kelompok mahasiswa penyaji didiskusikan dalam diskusi kelas. Kelompok penyaji dan seluruh mahasiswa dalam kelompok lain bersama-sama dengan dosen mendiskusikan hasil analisis Tsu yang dipresentasikan tersebut. Pembahasan ini difokuskan untuk membahas hasil analisis Tsu dari faktor intralinguistik maupun ekstralinguistik. Hal ini sesuai pendapat Robin (dalam Soemarno, 2001: 2) yang menegaskan bahwa, "Clearly the understanding of word and sentence meaning involves intralinguistic and extralinguistic factor". Dalam pernyataan tersebut terkandung maksud bahwa untuk memahami sebuah teks, faktor intralinguistik dan faktor ekstralinguistik merupakan faktor yang cukup penting untuk dianalisis dalam proses penerjemahan. Sesi ini adalah sesi penyajian.

Mahasiswa kelompok lain dan dosen mengajukan pertanyaan, memberi masukan, atau kritik tentang hasil analisis Tsu kelompok penyaji. Kelompok penyaji wajib menanggapi pertanyaan, kritik, atau saran dari mahasiswa lain dan dosen. Satu persatu hasil analisis kalimat tsu diulas dari aspek akurasinya. Setiap bagian kalimat yang dianalisis diulas perbagian mulai dari aspek satu dilanjutkan aspek berikutnya. Demikian seterusnya sampai pada analisis kalimat terakhir. Kegiatan ini dilakukan dalam sesi tanya jawab.

Dari hasil pembahasan ini, setiap mahasiswa wajib membuat revisi tentang analisis masing-masing bila hasil analisis tidak sesuai dengan hasil diskusi kelas. Hasil analisis Tsu individual dikerjakan dalam lembar kerjanya masing-masing. Hasil analisis Tsu yang telah direvisi dikumpulkan pada dosen untuk direkap sebagai rekap hasil revisi analisis Tsu. Kelompok penyaji membuat revisi hasil analisis dalam power point yang dipresentasikannya. Kegiatan ini dilakukan dalam sesi perbaikan. 
Pada pertemuan berikutnya, hasil revisi analisis Tsu individual dikembalikan dan dibagikan pada mahasiswa untuk didiskusikan lagi melalui diskusi kelas yang kedua. Kelompok penyaji mempresentasikan hasil analisis Tsu yang telah direvisi. Dalam presentasi hasil revisi analisis Tsu dalam diskusi kelas, kelompok penyaji mempresentasikan hasil revisi analisis Tsu kelompoknya. Setiap anggota kelompok penyaji mempresentasikan beberapa analisis kalimat dalam Tsu dan dilanjutkan anggota kelompok yang lain untuk analisis kalimat berikutnya. Mahasiswa dalam kelompok lain membandingkan hasil analisis Tsu kelompok penyaji dengan hasil analisis Tsu individual mereka masing-masing. Semua kegiatan ini dilakukan dalam sesi penyajian hasil revisi Tsu. Hasil revisi analisis Tsu ini dibahas dan didiskusikan oleh mahasiswa dan dosen untuk menentukan hasil analisis Tsu yang akurat dalam sesi penentuan hasil analisis. Selanjutnya, hasil analisis Tsu yang akurat ini dijadikan acuan bagi mahasiswa maupun dosen untuk melanjutkan praktik menerjemahkan pada tahap transferring dan restructuring.

Pada pertemuan berikutnya, kelompok yang lain mempresentasikan hasil analisisnya sesuai waktu presentasi yang telah ditentukan dan disepakati. Masingmasing kelompok mempresentasikan hasil analisis Tsu dari teks yang berlainan dari teks yang telah dipresentasikan terlebih dahulu oleh kelompok lain. Demikian juga, mahasiswa yang lain tetap menganalisis Tsu secara individual dalam buku kerjanya masing-masing melalui diskusi dengan anggota kelompoknya.

Catatan tentang hasil analisis individual mahasiswa itu dievaluasi pada akhir semester oleh dosen untuk mengetahui perkembangan kemampuan mahasiswa dalam menganalisis Tsu sehingga catatan itu bisa digunakan sebagai salah satu parameter untuk menilai kemampuan analisis Tsu mahasiswa.

Selama penerapan Student Team Achievement Division dan Group Investigation dalam mata kuliah translation 2 melalui observasi, wawancara, dan dokumentasi diketahui ada perubahan sikap, suasana kelas, dan prestasi mahasiswa. Hasil penelitian ini sesuai dengan penelitian yang dilakukan oleh Yunisrina Qismullah Yusuf, Yuliana Natsir, Lutfia Hanum (2015: 110). Hasil penelitian itu menunjukkan bahwa STAD adalah teknik pembelajaran yang sesuai diterapkan dalam kelas. Penelitian lain yang juga menunjukkan bahwa "group investigation cooperative learning" dapat meningkatkan keaktifan siswa dalam belajar adalah penelitian yang dilakukan oleh Harun Nasrudin dan Utiya Azizah (2010: 763).

\section{Kesimpulan}

Temuan yang dapat dikemukakan dalam penerapan STAD dan GI untuk menganalisis Tsu dalam praktik menerjemahkan dalam mata kuliah translation 2 yaitu: (1) semua kegiatan analisis Tsu dilakukan melalui sesi penyajian - tanya jawab perbaikan - penyajian hasil revisi analisis Tsu - penentuan hasil analisis, (2) hasil analisis Tsu pada beberapa teks bahasa sumber menunjukkan adanya peningkatan kemampuan analisis mahasiswa meskipun belum mencapai kemampuan yang sangat baik, (3) mahasiswa lebih antusias dalam menerjemahkan karena mahasiswa yang lebih rendah kemampuan analisisnya bisa menganalisis Tsu dengan berdiskusi dalam kelompok belajar dan diskusi kelas.

\section{Daftar Pustaka}

Isjoni. (2007). Cooperative Learning: Mengembangkan Kemampuan Belajar Berkelompok. Bandung: Alfabeta. 
Karnedi. (2004). Analisis Teks dalam Penerjemahan. Tangerang: Universitas Terbuka.

Miles, M.B. dan A. M. Huberman. (1994). Qualitative Data Analysis. Thousand Oaks: Sage Publications.

Nasrudin, H. dan Azizah, U. (2010). Improvement Thingking Skills And Scientific Attitude Using The Implementation O"Group-Investigation Cooperative Learning Contextual Oriented At Acid, Base And SaltTopic In Junior High School. Proceedings of The 4th International Conference on Teacher Education, 8-10 November, Join Conference UPI \& UPSI Bandung.

Nord, C. (1991). Text Analysis in Translation: Theory, Methods and Didactic Application of a Model for Translation-oriented Text Analysis. Amsterdam: Rodopi.

Soemarno, Th. (2001). The Problems of Culture in Translation, Munas IV dan Semnas II HIMABS1I 24-26 September Universilas Sanata Dharma Yogyakarta.

Sri Samiati. (2012). Semantik. Surakarta: UNS Press.

Sujono, Adiloka. (2014). Konstituensi dalam Proses Penerjemahan (Sebuah Tinjauan Singkat) (online). (http://download.portalgaruda.org/article.php?article=297277\&val=5319\&title=K ONSTITUENSI\%20DALAM\%20PROSES\%20PENERJEMAHAN\%20\%20(Sebu ah\%20Tinjauan\%20Singkat)) Diunduh 10 Agustus 2018

Yusuf, Y.Q., et.al., (2015). A Teacher's Experience in Teaching with Student TeamsAchievement Division (STAD) Technique, International Journal of Instruction, 8 (2). 